\title{
RACE WALKING: INVERSION OF FUNCTION FROM THE ASPECT OF SPEED AND RESULT SUCCESS
}

\author{
Ratko Pavlović1 ${ }^{1}$, \\ Borko Petrović, \\ Mensur Vrcić \\ ${ }^{1}$ Faculty of Physical Education and Sport, \\ University of East Sarajevo, \\ Bosnia and Herzegovina \\ ${ }^{2}$ Faculty of Physical Education and Sport, \\ University of Banja Luka, \\ Bosnia and Herzegovina \\ ${ }^{3}$ Faculty of Sport and Physical Education, \\ University of Sarajevo, \\ Bosnia nad Herzegovina
}

\begin{abstract}
:
Race walking (RW) is a cyclic athletic discipline, of aerobic character, which is characterized by high intensity and high energy consumption. The result is correlated with the anthropological dimensions of the walker as well as good technical performance. The study includes 25 male students, third year of study, Faculty of Physical Education and Sports in East Sarajevo. For the purposes of the research, the results of RW at $2 \mathrm{~km}$ (criterion variable) were measured, on the basis of which average values of walking speed (WS) were calculated. The aim of the research was to determine the correlation between the achieved result depending on the walking speed. By applying the Pearson product of the correlation moment, the obtained results confirmed a significant and high correlation between the result and the walking speed $(r=-0.988 ; \mathrm{p}<0.05)$ with an inverse function that confirms the high dependence of the result on the WS.
\end{abstract}

Key words: walking race, average speed, oscillations

\section{Introduction}

As an athletic discipline, sport walking made significant progress during the 18th century in England to the 1908 London Olympics (Kozloff, 2004). Since then, the performance of sport walkers has been constantly improving, until the Olympic Games in Mexico in 1968, when domestic walkers first demonstrated walking in a straight line with large rotations

i Correspondence: email pavlovicratko@yahoo.com 
of the pelvis. Until then, sport walking seemed like ordinary walking, only at a faster pace (Hanley, Bissas, \& Drake, 2011). Race walking is a cyclic movement, moderate to high intensity, which takes place in the sagittal plane, where the walker in aerobic mode completes 98\% of the path (Dvorak, et al., 1990). Chwala (2009) defines sport walking as a periodic movement divided into a support phase (cushioning and reflection) and the phase of swing (acceleration and braking) when characterized by synchronized movements of the cranial and caudal extremities. It has been documented in the literature that athletic (sport) walking is a middle mechanical type of movement, between walking and running (Hoga, Ae, Enomoto, Yokozawa, \& Fuji, 2006). Therefore, there are significant differences in kinematic and kinetic parameters between different types of walking (walking, race walking, running).

During the entire movement, the walker must maintain contact with the ground with one or both feet (Stanković, \& Raković, 2010; Pavlović, 2014). Sport walking, and consequently speed, are regulated by strict rules. In the basic structure of movement, sport walking is based on ordinary walking, but it also has its specifics: higher speed of movement, greater coordination of movements, complete straightening of the leg when placed on the ground, more pronounced movement of the pelvis and shoulder girdle, as well as active movements of constantly bent arms in back and forth direction (Idrizović, 2010; Mihajlović, 2010; Pavlović, 2014). Very often during the competition, at high walking speeds, the two-support phase is missing (the walker enters the flight phase) and they receive a warning or disqualification. However, regardless of the extremely high intensity of movement (over 220 steps/min), and speed (over $4.70 \mathrm{~m} / \mathrm{s}$ ), movements in sport walking should not be sudden, sharp or disrupt the rhythm of movement and consume energy for competitors. Therefore, during sport walking, larger oscillations in the sagittal plane and lateral shifts of the body's center of gravity in the horizontal plane should be avoided. Due to the fact that the way of athletic walking defined by the IAAF rules is not a naturally acquired human skill because normal walking and running are acquired in childhood, it is common for competitors to learn the technique of walking according to the instructions of the coach. Therefore, the number of walkers who have good enough techniques to participate and finish the race in major competitions (without disqualification) depends on coaches who can properly train the walking technique during the movement on the track (Hoga, 2011; Pavlović, \& Mihajlović, 2020). Technically good walker is characterized by softness and rhythm of movement, good coordination, especially in the movements of the shoulder and pelvic girdle. Earlier studies on athletic walking (Yoshida, Udo, Iwai et al. 1989) believe that success in competitions is associated with the ability to achieve and maintain high walking speeds on the track without accumulation of lactate in the blood, i.e. in aerobic mode, which leads to conflicting opinions (Drake, \& James, 2011). High speed in competition is one of the most important factors for achieving high performance in race walking.

Earlier research on sport walking techniques mainly analyzes walking technique, identifies differences between sport and normal walking, differences between sport walking and running, substrate reaction during walking, analysis of biomechanical characteristics (Murray, Guten, Mollinger et al., 1983; Fenton, 1984, White, \& Winter, 
1985, Cairns, Burdette, Pisciotta et al., 1986, Hanley, Drake, \& Bissas, 2008; Hanley, Bissas, \& Drake. 2008; Vernillo, Agnello, Drake, Padulo, Piacentini, \& Torre, 2012; Sovenko, Budkevych, \& Lytvynchuk 2014). Authors Gomez-Ezeiza, Torres-Unda, Tam, Irazusta, Granados, \& Santos-Concejero (2018) analyze the relationship between the biomechanical parameters of the walking cycle and the economics of walking of world-class Olympic walkers, as well as the spatio-temporal parameters of walking at different speeds. The obtained result in walking $20 \mathrm{~km}$ is related to the economy of walking on the track, because the fastest runners show lower oxygen consumption at a given speed. Also, a longer contact phase, a shorter flight time, a longer sub-phase of the middle position and a shorter propulsive phase during the position are associated with better economy of walking technique on the track. Therefore, coaches and competitors should avoid changing the style of racing by increasing the flight time. This can not only disrupt the economy of the movement, but also lead to a referee warning which reduces the speed of the walker as a result of some kind of fear of disqualification (Alves, Cruz, Domingos, Osiecki, De Oliveira, \& Lima, 2018).

Pavei, \& La Torre (2016) analyze the differences in techniques at the level of athletes (regional, national, international) and describe the kinematics of racing at high speeds. The obtained results show that the length, step frequency and flight time increase linearly with speed, where the step length is the main factor for increasing the speed. Among the levels of athletes, the only difference found relates to the maximum walking speed (international $4.97 \mathrm{~m} / \mathrm{s}$; national $4.61 \mathrm{~m} / \mathrm{s}$, regional $4.22 \mathrm{~m} / \mathrm{s}$ ). Also, the results show that the angular kinematics of the athlete does not affect the changes in the speed of the walker on the track. The speed of movement of top competitors exceeds 2-3 times the speed of ordinary walking, which is on average about $5 \mathrm{~km} / \mathrm{h}$. The length of the walking step is close to $90 \mathrm{~cm}$, and the sport walking step goes up to $130 \mathrm{~cm}$, which is correlated with the length of the caudal extremities and the strength of the walking muscles. In normal walking, the frequency of steps is 110-120 steps/min, and in sports 180-230 steps/min (Mihajlović, 2010; Idrizović, 2010; Stanković, \& Raković, 2010, Pavlović, 2014). However, there are few studies that investigate the effects of the speed of normal-pace walking and sport walking. Murray, Guten, Mollinger, \& Gardner, in 1983, compared normal brisk walking with sport walking and found that sport walking causes higher speeds due to increased length and frequency of steps, which consequently increased muscle activation. Similar to previous research, Cairns, Burdett, Pisciotta, \& Simon (1986) compare normal walking, slower and faster walkers in sport walking. The increase in speed in sport walking caused an increase in step length and frequency. The increase in step frequency resulted in reduced contact time. They also concluded that speed oscillations changed walking characteristics, including joint kinematics and ground reaction forces, indicating increased muscle force generation and mechanical work. Studies during high-level sport walking competitions gave higher speeds than those reported during laboratory studies, where the average speed of the world record in sport walking during races was $10 \mathrm{~km}(4.36 \mathrm{~m} / \mathrm{s})$ and $50 \mathrm{~km}(3.89 \mathrm{~m} / \mathrm{s})$. Therefore, the biomechanical aspect of movement during sport walking seems to play a crucial role in energy expenditure and movement mechanics (Minetti, Ardigo, \& Saibene, 1994). 
Although taking into account the kinematic parameters can define the athlete's efficiency, no previous study has investigated the kinematic characteristics of sport walking uphill and at different speeds. Sport walking uphill is used as a training method to improve cardiovascular and muscular strength such as aerobic strength and moving the lactate threshold (La Torre, 2010). Minetti, Moia, Roi, Susta, \& Ferretti (2002) compared energy consumption during normal walking and running in positive and negative slopes. The results confirmed that the walking speed is higher on flat terrain and is reduced by increasing the slope. It is appropriate to understand the kinematic adaptations of changes in the speed of sport walking. Padulo, Annino, D'Ottavio, Vernillo, Smith, Migliaccio, \& Tihanyi (2013) analyze the effects of different velocities on the lane $(3.61 \mathrm{~m} / \mathrm{s} ; 3.89 \mathrm{~m} / \mathrm{s} ; 4.17 \mathrm{~m} / \mathrm{s})$ and slope $(0,2-75 \%)$ on kinematic parameters (stride length, stride frequency and contact time) during sport walking of elite walkers. The results show that the increase in stride length is linearly associated with an increase in velocity $\left(\mathrm{r}=0.3 \mathrm{p}^{\mathrm{p}<0.01}\right)$, while reductions in stride length are caused by an increase in slope $\left(\mathrm{r}=-0.56, \mathrm{p}^{<0.0001}([0-2 \%=-3.5 \%, \mathrm{p}<0.02],[0-7 \%=-7.5 \%, \mathrm{p}<0.01])\right.$ The step frequency is positively correlated with the increase in speed $(\mathrm{r}=0.56), \mathrm{p}=0.0001)$ and slopes $(\mathrm{r}=0.50, \mathrm{p}<0.0001(0-2 \%=3.6 \%$; $\left.0-7 \%=8.5 \%,{ }^{\mathrm{p}<0.01}\right)$. therefore, the contact time is negatively correlated with an increase in both velocity $(\mathrm{r}=-0.57, \mathrm{p}<0.0001)$ and inclination $(\mathrm{r}=-0.50, \mathrm{p}<0.0001(0-2 \%=-3,4 \%, 0-7 \%-7.7 \%, \mathrm{p}<0.01)$ These results suggest that the use of slopes $<7 \%$ could significantly change the neuromechanical behavior of athletes, while slopes of about $2 \%$ could positively affect performance of elite runners without changing running technique. According to Pupiš, \& Čillík (2005) the intensity of the walker's load at 50km reaches a value of 93 to $97 \%$ of the anaerobic threshold, and at $20 \mathrm{~km}$ it increases to $104 \%$ of the anaerobic threshold with high intensity on the track (HR 175-185bpm), which is manifested on the walker's body subjective feelings of fatigue. In the body of a competitor, it is possible to objectively monitor changes in chemical composition and related physiological processes, such as an increase in resting heart rate or changes in body temperature. With increasing walking speed, the length and frequency of steps usually increase as well (Wieslaw, Waclaw, \& Krzysztof, 2011; Pavlović, 2014). According to Hanley, Bissas, \& Drake (2011) the development and maintenance of efficient walking is crucial in a unique sport walking movement, where the result of walking is inversely related to the average walking speed (the better result is represented by a numerically lower value and the average walking speed is a numerically higher value). Technically, the movement of the walker should be even, rectilinear for the economy of movement and without excessive energy consumption. According to Pavlović, \& Mihajlović (2020), it is best to walk with optimal parameters of step length and frequency, taking into account the individual characteristics of the walker, body height, body weight, BMI, functional abilities and, of course, movement technique.

The idea for this study came from the fact that Race walking is studied within the athletics module at the Faculty of Physical Education and Sports, where students through the practical part are created by getting to know, training and perfecting the technique of Race walking. Having in mind all previous laws regarding the success rate, 
biomechanical and functional parameters, the goal of the study is defined, which seeks to determine the results of the connection with the walking speed on the section of $2 \mathrm{~km}$.

\section{Method}

The study included 25 male third-year students (Height $=182.20 \pm 5.89 \mathrm{~cm}$; Weight $=79.68$ $\mathrm{kg} \pm 7.59 ; \mathrm{BMI}=24.01 \pm 2.18 \mathrm{~kg} / \mathrm{m}^{2}$ ) who took the practical exam in Athletics. As a criterion variable, the achieved result was race walking $2 \mathrm{~km}$. Based on the physical formula:

$$
S(\text { path })=V(\text { speed }) \times t(\text { time }),
$$

The formula for speed is derived on the basis of which the necessary parameters are obtained, the average speed of the entire sample is calculated as well as individual average student results and the linear function is defined. Based on the results of RW $2 \mathrm{~km}(\mathrm{~min})$, the achieved WS (m/s) were calculated.

\subsection{Statistical Analysis}

Basic central and dispersion parameters were calculated for all subjects. After the assumption of normality, verified by the Kolmogorov-Smirnov test, the Pearson productmoment correlation model was applied and the degree of correlation of the velocity with the result for the level $\mathrm{p}<0.05$ was determined. Statistical analysis was performed using statistics software 10.0 .

\section{Results}

Table 1: Basic statistical parameters

\begin{tabular}{|l|c|c|c|c|c|c|c|}
\hline & Mean & Min & Max & Rang & SD & CV\% & K-S \\
\hline RW results (min) & 14,58 & 13,05 & 17,33 & 4,28 & 1,280 & 8,60 & 0,119 \\
\hline WS (m/s) & 2,23 & 1,89 & 2,55 & 0,660 & 0,189 & 8,72 & 0,103 \\
\hline
\end{tabular}

Table 2: Pearson-product moment correlation $(\mathrm{p}<0,05)$

\begin{tabular}{|l|c|c|}
\hline & Walking (result) & WS (m/s) \\
\hline RW result (min) & 1,000 & \\
\hline WS (m/s) & $-0,988 \quad \mathrm{p}=0,00$ & 1,000 \\
\hline
\end{tabular}

The obtained research results on a sample of students (Table 1) showed that the average achieved RW result was $14.58 \mathrm{~min}$. The best result of an individual is 13.05 minutes and the weakest $17.33 \mathrm{~min}$. The average total WS ranged from a minimum of $1.89 \mathrm{~m} / \mathrm{s}$ to a maximum of $2.55 \mathrm{~m} / \mathrm{s}$ with an average speed of $2.23 \mathrm{~m} / \mathrm{s}$. Pearson's coefficient showed a high inverse correlation of the results with the walking speed $(\mathrm{r}=-0.988, \mathrm{p}=0.01)$. Assumption is that the best student had the highest average speed of movement and that this is the inverse relationship of the function (Table 2, Graph 1). The results depict the correct distribution as a consequence of a chronologically uniform sample of students, in relation 
to their motor and functional abilities, which are often an indicator of physical ability (Pavlović, \& Mihajlović, 2020). It is a sample that is in the phase of changes in terms of motor and functional space, unlike e.g. body height which records stagnation in this period in relation to mass and total BMI. Also, the results in RW (mean=14.58 min) are a consequence of previous changes in morphological, motor and functional parameters that are not included in the research, but their impact is felt. Students who had a better result had better technical performance, better aerobic power. These results are also expected, since the result success, in addition to the above parameters, depends on the movement technique, especially if it is a longer distance (Brodáni, Šelinger, \& Vavák, 2011), while at shorter distances there is a more pronounced effect of anaerobic-aerobic abilities, length and frequency of movements, while morphological indicators are not fully manifested. This is especially evident with beginners, who are not sports walkers but come from various other spheres of sports disciplines, most often sports games, martial arts, athletic running, jumping and throwing disciplines, which was shown in this sample of students of physical education and sports. There is an evident trend of a linear increase in the results of walking among students from the minimum (best) result of 13.04 minutes to the maximum (the worst time) result of 17.33 minutes. In terms of walking speed, there is a slight decrease, from a maximum of $2.55 \mathrm{~m} / \mathrm{s}$ to $1.89 \mathrm{~m} / \mathrm{s}$. This relationship is an obvious indicator of the inverse relationship between results and students' walking speed (Graph 2).

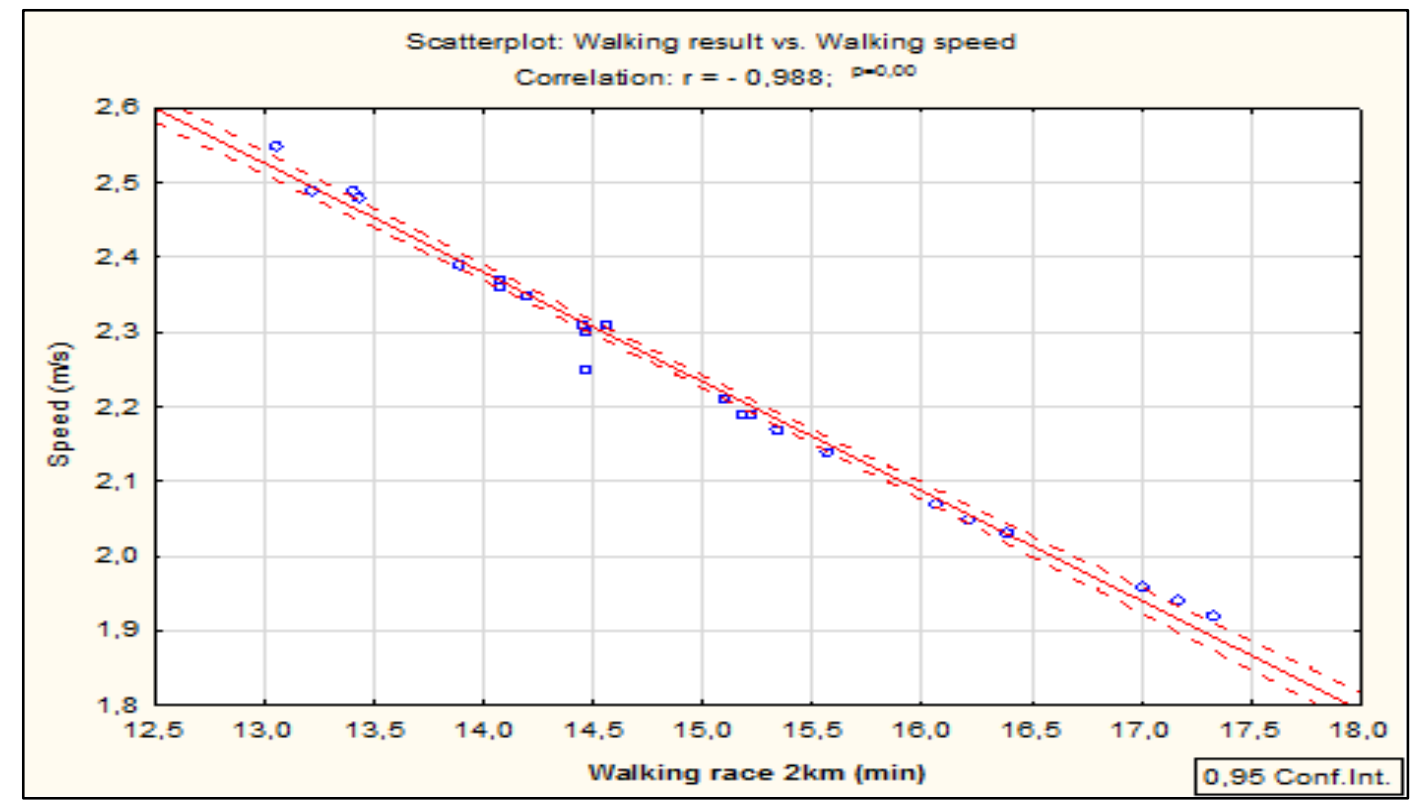

Graph 1: Correlation of results and walking speed 


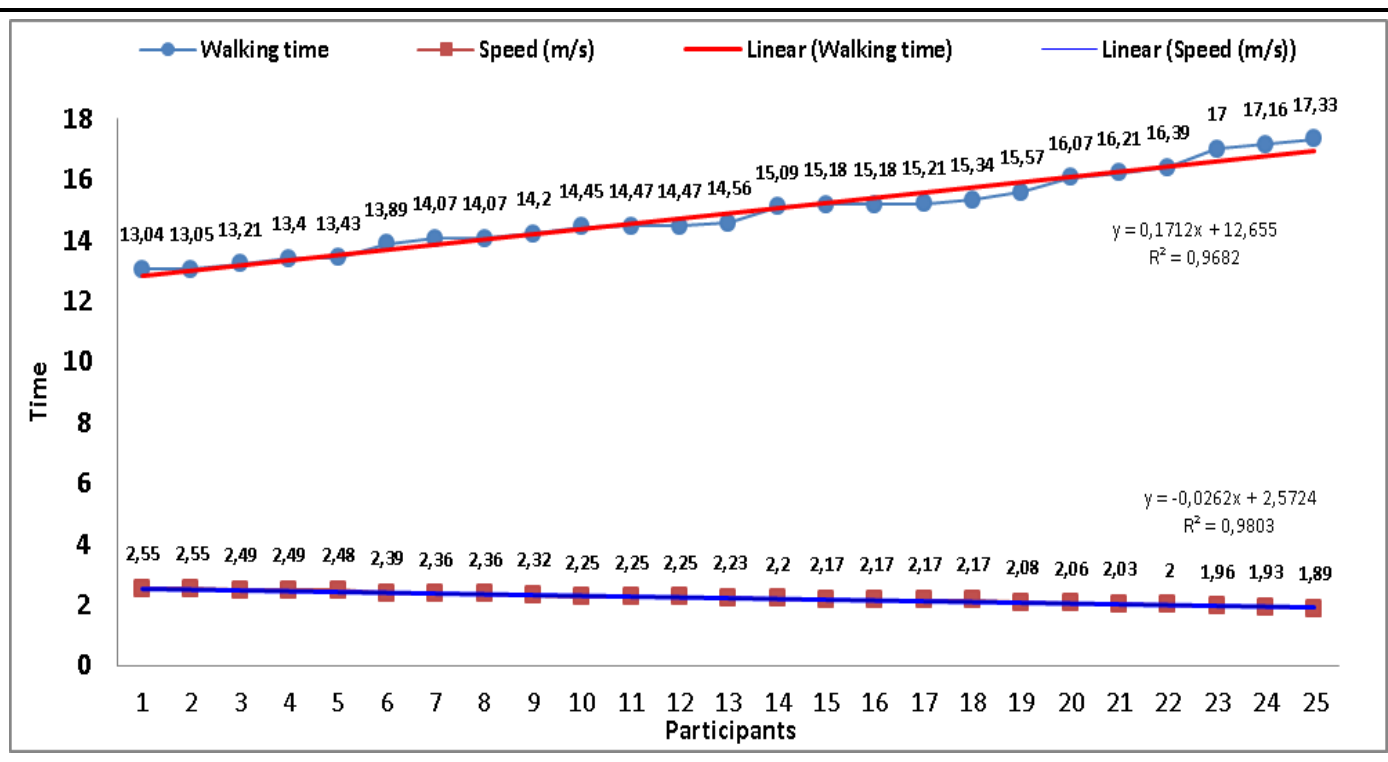

Graph 2: The function of result performance depending on speed

\section{Discussion and Conclusion}

This study was conducted with the aim of determining the relationship between the results of race walking and the average walking speed of a sample of students at $2 \mathrm{~km}$. Pearson's correlation product is quite high $(\mathrm{r}=-0.988)$, which confirmed the dependence of the results on the speed of movement (frequency + step length). It is evident that morphological, motor, and most functional parameters contributed to the distribution of results. The results and walking speed are related to the aerobic-anaerobic processes in the body, the way of energy consumption and the degree of adoption of the student's walking technique. A significant correlation was achieved between these two parameters. However, more can be discussed about the necessity of the realization of kinematic parameters, the function of organic systems, performance in athletic walking and of course the technical performance of each individual as well as the spatial-temporal parameters. These results are consistent with the results of previous research (Brodani, \& Schelling, 2001; Brodani, Vavák, \& Schelling, 2003; Gomez-Ezeiza, Torres-Unda, Tam et al., 2018; Pavlović, \& Mihajlović, 2020).

According to Dodig (2002), the kinetic structure of walking belongs to the space of cyclic motions, which is characterized by each cycle representing a series of specifically related spatial motions that are alternately repeated using a solid surface. Success in athletic walking requires a high level of technical ability and physical endurance, where any inefficiency in the movement of a sport walker increases energy costs, the risk of early fatigue or disqualification. During normal walking, vertical deviations range from 4-6 cm, and horizontal (lateral) deviations from 2-12 cm. However, in walkers with a wellperfected technique, these oscillations are significantly reduced using the solid substrate (Rp) reaction, which moves the walker's body forward based on inertial reactive forces (Pavlović, \& Mihajlović, 2020). Vanderka (2008) believes that the basic principle that defines the results of sport walking is the time or speed for which a certain distance is covered (the relationship between frequency and stride length), or intramuscular 
coordination and flexible kinetic mechanism, which allows walkers to increase their efficiency with minimal energy consumption. This principle has proven to be correct here even though it is about subjects who are not yet technically at an enviable level, which is related to the increased concentration of lactate in the blood, confirming previous research (Yoshida, Udo, Iwai et al., 1989). The obtained results of the current sample in terms of kinematics show that the length, step frequency and flight time increase linearly with speed, where stride length was the main factor for increasing speed, which is consistent with the results (Murray, Guten, Mollinger, \& Gardner, 1983; Cairns, et al., 1986; Padulo et al., 2013; Pavei, \& L. Tore, 2016).

It is known that the dynamics of sport walking is achieved by prolonging the walking stride, the duration of the contact phase and reducing the frequency. Irregularities in the kinematic parameters are noticed only by achieving the walking speed at the level of the required pace, which is characteristic for a given discipline (Pavlović, \& Mihajlović, 2020). Taking into account the mentioned dynamics of walking step, the technique of walking is possible by developing intramuscular and muscular coordination and using flexible movement of the kinetic composition of the organism (Brodáni, Šelinger, \& Vavák, 2011). Weaker results within our sample can be characterized by weaker muscle activation and overall mechanical work as a consequence of the substrate reaction which is a crucial factor in energy consumption andmovement mechanics which fully supports the study (Minett, Ardigo, \& Saibene, 1994). Precisely these specifics are evident in our judge, where students due to poorer walking technique neglected this important segment that could result in better individual placement. Practice shows that the effect of inheriting the economy of walking step depends on the years of training experience, so in the opinion (Brodani, et al. 2011) one must work not only on the physical readiness of competitors, but also on the technique of walking kinetic manifestation. Rational technique is characterized by minimizing the reduction of speed within the touch of the vertical line, which affects the level of functionality of the flexors and gluteal muscles, as well as a higher level of special abilities (Kampmiller et al., 1998; Brodani et al. 2003). Lateral and vertical oscillations of the walker are the basic determinants of athletic walking, and the most important are the rotation and inclination of the pelvis. It has also been found that pelvic tilt increases in athletic walking relative to normal walking and running (Cairns, et al. 1986), that pelvic movements through minimal vertical oscillations of TT reduce energy expenditure (Ruhling, \& Hopkins, 1990) and help in reducing the occurrence of flight (Villa, 1990). Effective pelvic girdle control is especially important in increasing the speed of athletic walking, because pelvic rotation increases stride length (Murray, et al. 1983; Knicker, \& Loch, 1990) and stride frequency (Fruktov, Korolyov, \& Ozerov, 1984) and allows additional muscle groups are used to move the legs forward, not just because of the greater range of the walking stride (Trowbridge, 1981).

There is not enough scientific evidence on how to formulate recommendations for athletic walking training for both coaches and athletes. This is especially evident when many methodological factors related to athletic walking are taken into account, which coincide with the maximum oxygen consumption, Lactate threshold, Energy 
consumption (Pavlović, \& Mihajlović, 2020). There is a general lack of specific knowledge, and coaches should be shifting major discoveries in the scientific literature of athletic walking training, combining practical experience with theoretical knowledge, as very often physiological stress, energy expenditure or physiological determinants are important for athletic walking performance (La Torre, \& Vernillo , 2011), which can be said for the results of this research.

The research was realized with the aim of examining the relationship between the results of walking at $2 \mathrm{~km}$ depending on the walking speed of students of physical education and sports. The Pearson-moment correlation was analyzed. Based on the obtained results, a significant high correlation of the two systems was confirmed ( $\mathrm{r}=-$ 0.988; $\mathrm{p}<0.05$ ) with an inverse function which confirms the high dependence of the results on the walking speed.

\section{Conflict of Interest Statement}

The authors declare no conflicts of interests.

\section{About the Authors}

Ratko Pavlović is Professor Sports and Rehabilitation Sciences at Faculty of Physical Education and Sport, University of East Sarajevo. His current research interests are Track and Field, Kinanthropometry, Sports Science, Motor Skills, Biomechanics of Sport. (email: pavlovicratko@yahoo.com)

Borko Petrović is Associate Professor Sports and Rehabilitation Sciences at Faculty of Physical Education and Sport, University of Banja Luka. The research interests are Kinesiology, Anthropometry, Motor Control, Sports Science, Motor Skills, Sport Training. (email: borko.petrovic@ffvs.unibl.org)

Mensur Vrcić is Associate Professor at Faculty of Sport and Physical Education, University of Sarajevo. Areas of research include Athletic Throwing, Sports Recreation and Fitness Programs (email: mvrcic41@gmail.com)

\section{References}

Alves, DL., Cruz, R., Domingos, PR., Osiecki, R., De Oliveira, FR., Lima, JP. (2018). Do warnings received in race walking influence the speed of athletes? International journal of Performance Analysis in Sport. 18 (3), 463-469.

Brodani, J., \& Šelinger, P. (2001). Dynamics of pedestrian step changes as the speed of walking is increased. In ATLETIKA 2001. Banská Bystrica: UMB, (p 34).

Brodáni, J., Vavák, M., Šelinger, P. (2003). The share of kinematic indicators on the speed variability of a pedestrian step. Studia Kinanthropologica - The Scientific journal for Kinanthropology. 4 (2),75-80.

Brodáni, J., Šelinger, P., \& Vavák, M. (2011). Athletic Walking in Terms of Kinematic Parameters of Walking Step. In monography (Ed.). M.Pupiš et al. World race walking research (162-170). 
Cairns, M., Burdette, R., Pisciotta, J., \& Simon, S. (1986). A biomechanical analysis of racewalking gait. Medicine and Science in Sport and Exercise, 18(4), 446-453.

Chwała W. (2009) Influence of space-time parameters on oscillations of the general center of gravity OSC in the function of increasing speed of sports walk in the group of master class walkers, In: Urbanik, Cz., Mastalerz, A., (ed.), Biomechanics of sport and rehabilitation - selected issues, Oficyna Drukarska Jacek Chmielewski, University of Physical Education in Warsaw, (pp.29-43).

Dvorák, M. et al. 1990. Methodical sheets 18. Preparation of Czechoslovak pedestrians for the Olympic Games in Seoul - 1988. Prague. VMOÚU ŠTV. (p.72).

Dodig, M (2002). Modeli i modeliranje tjelovježbovnih procesa [Models and modeling of exercise processes. In Croatian] Rijeka: Sveučilište u Rijeci.

Drake, A.,\& James, R. (2011). Prediction of Race-Walking Performance Via Laboratory and Field Tests. In monography (Ed.). M.Pupiš et al. World race walking research (pp.71-79)

Fenton, R. M. (1984). Race walking ground reaction forces. In: J. Terauds ed., Research Center for Sports, Del Mar, California, 61-70.

Fruktov, A., Korolyov, G., \& Ozerov, V. (1984). Technique and faults in race walking. Modern Athlete and Coach, 22(3), 35-37.

Gomez-Ezeiza, J., Torres-Unda, J., Tam, N., Irazusta, J., Granados, C., \& Santos-Concejero, J. (2018). Race walking gait and its influence on race walking economy in worldclass race walkers. Journal of Sport Sciences, 36 (19), 2235-41

Hanley, B., Drake, A., Bissas, A. (2008). The biomechanics of elite race walking: technique analysis and the effects of fatigue. New studies in athletics, (4), 17-25.

Hanley, B., Bissas, A., Drake, A. (2008). Initial findings of a biomechanical analysis at the 2008 IAAF World Race Walking Cup. New studies in athletics, (4), 27-34.

Hanley, B., Bissas, A., \& Drake, A. (2011). The Biomechanics of Efficient Race Walking. In monography (Ed.).M.Pupiš et al. World race walking research (pp.171-192)

Hoga K, Ae, M., Enomoto Y, Yokozawa T, Fujii N. (2006). Joint torque and mechanical energy flow in the support legs of skilled race walkers. Sports Biomech. (5), 167182.

Hoga, K. (2011). Mechanical Energy Flow Between Body Segments on Race Walking. In monography (Ed.).M.Pupiš et al. World race walking research (pp.113-129)

Idrizović, K. (2010) Atletika I i II. [Athletics I-II. In Serbian]. Univerzitet Crne Gore: Biblioteka biomedicinskih nauka.

Kampmiller, T., Vavák, M. Laczo, E. \& Šelinger, P. (1998). Analysis of kinematic structure of athletics walking. In Seminar for Race Walking Coaches. Bratislava. (pp.37-53).

Knicker, A., \& Loch, M. (1990). Race walking technique and judging - the final report of the International Athletic Federation research project. New Studies in Athletics, 5(3), 25-38.

Kozloff, E. H. (2004). Edward Payson Weston and the 1861 Inauguration: the feats of the "pedestrians" of the 19th century continue to astonish historians of running. Marathon and Beyond, 8(6), 122-138. 
Murray, M. P., Guten, G. N., Mollinger, L. A., \& Gardner, G. M.(1983). Kinematic and electromyographic patterns of Olympic race walkers. The American Journal of Sports Medicine, 11(2), 68-74.

Minetti AE, Ardigo LP, Saibene F. (1994). Mechanical determinants of the minimum energy cost of gradient running in humans. J Exp Biol 195: 211-225, 1994.

Minetti AE, Moia C, Roi GS, Susta D, Ferretti G. (2002). Energy cost of walking and running at extreme uphill and downhill slopes. J Appl Physiol. (93), 1039-1046.

Mihajlović, I (2010). Atletika. [Athletics. In Serbian]. Novi Sad: Fakultet sporta i fizičkog vaspitanja

Pavlović, R. (2014). Atletika 1. [Athletics I. In Serbian]. SIA. Niš

Pavlović, R., \& Mihajlović, I. (2020). Race Walking: Morphological and Motor-Functional Parameters as Success Factors. Physical Culture. Sport. Tourism. Motor Recreation, 5 (1), 103-111. Chelyabinsk State University.

Pupiš, M., \& Čillík, I., (2005). Load intensity at endurance performance. In: Athletics 2005, Prague: Falon.

Pavei, G., La Torre, A. (2016). The effects of speed and performance level on race walking kinematics. Sport Sci Health 12, 35-47. https://doi.org/10.1007/s11332-015-0251-z

Padulo, J, Annino, G, D'Ottavio, S, Vernillo, G, Smith, L, Migliaccio, GM, and Tihanyi, J. (2013). Footstep analysis at different slopes and speeds in elite race walking. $J$ Strength Cond Res 27(1), 125-129.

Ruhling, R. O., \& Hopkins, J. A. (1990). Race Walking. In: Reilly, T. ed. Physiology of Sports, London, E and FN Spon, 153-171.

Stanković, D., \& Raković, A. (2010). Atletika [Athletics. In Serbian] Niš: Fakultet sporta i fizičkog vaspitanja.

Trowbridge, E. A. (1981). Walking or running - when does lifting occur? Athletics Coach, $15(1), 2-6$.

La Torre, A. (2010). The $20 \mathrm{~km}$ of travel by Ivano Brugnetti [Italian]. Edizione Fidal: Atletica Studi.

La Torre, A., \& Vernillo, G. (2011). The Training for the 20-Km. What Has Changed and What Might Change? In monography (Ed.). M.Pupiš et al. World race walking research (pp.80-94)

Villa, F. (1990). NSA photo sequences 12 and 13: race walking. New Studies in Athletics, 5(3), 63-68.

Vanderka, M. (2008). Strength and speed skills in fitness training of athletes. Bratislava: ICM Agency, (p92).

Sovenko S.P., Budkevych H.B., Lytvynchuk T.V. (2014). Technical specifications of qualified sportswomen who specialize in race walking for $10 \mathrm{KM}$. Physical education of students. 8 (4), 37-41.

Vernillo G, Agnello L, Drake A, Padulo J, Piacentini MF, La Torre A. (2012). An observational study on the perceptive and physiological variables during a 10,000$\mathrm{m}$ race walking competition. J Strength Cond Res. 26(10),2741-7. doi: 10.1519/JSC.0b013e318242a33c. 
Yoshida, T., Udo, M., Iwai, K., Muraoka, I., Tamaki, K., Yamaguchi, T., \& Chida, M. (1989). Physiological determinants of race walking performance in female race walkers. British Journal of Sports Medicine, 23 (4) 250-254.

White, S.C., \& Winter, D.A. (1985) Mechanical power analysis of the lower limb musculature in race walking. International Journal of Sport Biomechanics, 1 (1), 15-24.

Wiesław, C., Wacław, M., \& Krzysztof, K. (2011). The Modern Instruments of Kinematic and Kinetic Technique Evaluation at the Competitors Practicing Race Walking. In monography (Ed.). M.Pupiš et al. World race walking research (193-212). 
Creative Commons licensing terms

Authors will retain the copyright of their published articles agreeing that a Creative Commons Attribution 4.0 International License (CC BY 4.0) terms will be applied to their work. Under the terms of this license, no permission is required from the author(s) or publisher for members of the community to copy, distribute, transmit or adapt the article content, providing a proper, prominent and unambiguous attribution to the authors in a manner that makes clear that the materials are being reused under permission of a Creative Commons License. Views, opinions and conclusions expressed in this research article are views, opinions and conclusions of the author(s). Open Access Publishing Group and European Journal of Physical Education and Sport Science shall not be responsible or answerable for any loss, damage or liability caused in relation to/arising out of conflict of interests, copyright violations and inappropriate or inaccurate use of any kind content related or integrated on the research work. All the published works are meeting the Open Access Publishing requirements and can be freely accessed, shared, modified, distributed and used in educational, commercial and non-commercial purposes under a Creative Commons attribution 4.0 International License (CC BY 4.0). 